\title{
LA-UR-19-32626
}

Approved for public release; distribution is unlimited.

Title:

Author(s):

Intended for:

Issued:
FY20 HR-ITS Customer Service Agreement

Rinke, Helen Mae

Training

2019-12-19 
Disclaimer:

Los Alamos National Laboratory, an affirmative action/equal opportunity employer, is operated by Triad National Security, LLC for the National Nuclear Security Administration of U.S. Department of Energy under contract 89233218CNA000001. By approving this article, the publisher recognizes that the U.S. Government retains nonexclusive, royalty-free license to publish or reproduce the published form of this contribution, or to allow others to do so, for U.S. Government purposes. Los Alamos National Laboratory requests that the publisher identify this article as work performed under the auspices of the U.S. Department of Energy. Los Alamos National Laboratory strongly supports academic freedom and a researcher's right to publish; as an institution, however, the Laboratory does not endorse the viewpoint of a publication or guarantee its technical correctness. 


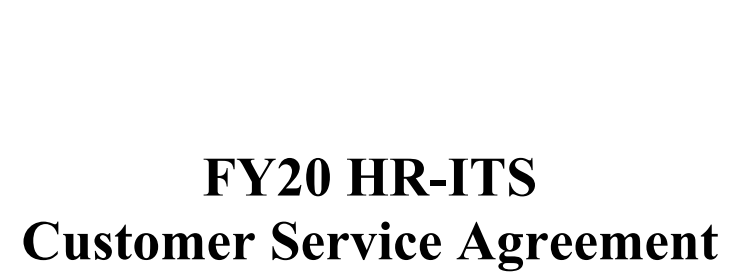

CSA \#: 20-

\section{Purpose and Terms}

The purpose of this Customer Service Agreement (CSA) is to formalize the agreement between HR-ITS and a customer who requires services. This agreement describes the specific services to be provided by HR-ITS and the costs that the customer agrees to pay for such services.

This agreement will remain in effect through the designated end date. Any project that continues beyond one year will be subject to mandatory review to evaluate progress and determine resources needed for completion.

Cost increases or decreases will be limited to changes in the LANL standard labor rates or changes in hours of services provided because of changes in the scope of this agreement. Any additional major content/design revisions (outside of the scope) could delay project completion and require additional funding from the customer. HR-ITS will charge only for time worked on the project.

\begin{tabular}{|c|c|c|}
\hline \multicolumn{3}{|c|}{ Project/Course/Program Description } \\
\hline \multicolumn{2}{|c|}{ Project/Course/Program Name: } & \multirow{2}{*}{$\begin{array}{l}\text { Course \#: } \\
\text { Phone: }\end{array}$} \\
\hline Customer Name: & Organization: & \\
\hline \multicolumn{3}{|c|}{ Project/Program Scope Summary: } \\
\hline \multicolumn{3}{|c|}{ HR-ITS Deliverables: } \\
\hline Start Date: & \multicolumn{2}{|l|}{ End Date: } \\
\hline
\end{tabular}

\section{Resources Provided by the Customer (check those that apply):}

Any site-specific training required to ensure ES\&H requirements are met, including relevant hazard communications.

Adequate and ergonomically appropriate work space for on-site support personnel, equipment repair, equipment storage, and/or setup. Consideration of work surface heights for keyboard, mouse, and monitor; lighting and noise levels, etc., is required to meet accepted property safety and security standards.

Software needed to perform the work.

Travel costs to remote locations covered in this agreement.

Adequate space and environmental conditioning for all systems covered in this agreement. 
CSA \#: 20-

\begin{tabular}{|clll|}
\hline Cost Estimate & & & \\
\hline $\begin{array}{c}\text { Project Based: } \\
\text { hours @ \$ }\end{array}$ & /hr. for & $\$$ & 0.00 \\
\hline hours @ \$ & /hr. for & $\$$ & 0.00 \\
\hline hours @ \$ & /hr. for & $\$$ & 0.00 \\
\hline hours @ \$ & /hr. for & Total Cost: & $\$$ \\
\hline & \% Deployed & & 0.00 \\
\hline Deployed Personnel: & $/$ & & \\
\hline Customer Charge Code: & / & & \\
\hline
\end{tabular}

\section{The following requirements may apply to this CSA (check those that apply):}

All Systematic Approach to Training (SAT) documentation must be completed for any new or revised course and must be available to the ITS-ID Team, if needed.

$\mathrm{SME}(\mathrm{s})$ have reviewed and approved the course content.

All course materials must be reviewed by a Derivative Classifier (DC).

All images, photos, and media must be reviewed and determined to be free of copyright infringements.

All course content must be submitted to (editor and/or content developer) by $\quad$ to meet the CSA deadline.

All interim or final product reviews must be completed within business days of receipt to meet CSA deadline.

A Laboratory-wide Training Requirements Analysis Form must be completed/approved for any new or substantively changed Laboratory-wide course (according to P781-1, Conduct of Training).

Large-audience courses (new or revised courses) will require training instance set-up/testing to ensure all UTrain settings are functioning properly before full-scale implementation of the course. HR-ITS or SAE-4 will assist with the set-up/testing of the course implementation.

Other (add other requirements here):

\begin{tabular}{|l|l|l|l|}
\hline Approvals & Title & Organization & Signature \& Date \\
\hline Name & & & \\
\hline HR-ITS Point of Contact (POC) & & & \\
\hline HR-ITS Manager & & & \\
\hline Budget Analyst & & & \\
\hline
\end{tabular}

Return the approved CSA by email to the HR-ITS POC listed above. 